\title{
FORMAS DE LA RELIGIOSIDAD EN LA LITERATURA ALEMANA ANTIGUA
}

\author{
Fernando Magallanes Latas
}

\begin{abstract}
This article presents an analysis of German religious literature from its origins to the Baroque, while it holds a classification from the point of view of textual typology. The issue is also seen taking as a starting point the concept of irrationality, connecting it with that of theological rationality. The purpose is to show not only the absence of antinomy but also the perfect compatibility of both principles when religious literature is dealt with.
\end{abstract}

Cuando nos referimos a literatura alemana antigua no pensamos únicamente en aquella primigenia del alborear lingüístico alemán, sino en toda una fase de la historia cultural y literaria que culmina en la Ilustración, en el șiglo XVIII como momento inicial de una auténtica y autóctona expresión artística de cuño netamente alemán que se irradia hacia el exterior proyectando desde entonces valores estéticos e influyendo en otros entornos del mundo occidental. Edad Media, Renacimiento y Barroco son por tanto etapas de esa cultura que llamamos antigua por dos motivos: en primer lugar, porque hasta finalizar el XVII la dependencia respecto del extranjero es bien patente desde el Alexanderlied, de mediado el siglo XII, con el que da comienzo la penetración cultural francesa en Alemania, pasando por toda una serie de siglos receptivos al humanismo italiano, la literatura inglesa o la picaresca española; y, en segundo lugar, porque la pervivencia de lo medieval en las primeras centurias de la Edad Moderna es evidente en una sociedad alemana que no alcanza el desarrollo de los países de su entorno sino hasta épocas más tardías.

Pues bien, en gran medida, la producción literaria alemana en esa primera fase de su desarrollo se halla estrechamente vinculada a lo religioso, de la misma manera que -singularmente en el medievo- sucede con los demás países europeos. Y la religión no es sino una vía de comprensión y postura ante la realidad, en principio, próxima a lo irracional. Sin embargo, este término y el concepto que encierra dista bastante de poder ser captado de manera unívoca, en concreto en el caso de la materia que nos ocupa: la literatura religiosa.

Ciertamente, lo irracional es objeto apropiado de los estudios filosóficos, y asunto escurridizo por su propia naturaleza. En efecto, una de las explicaciones de la racionalidad que ofrece la Filosofía es aquella que dice que la racionalidad existe cuando se expresan "proposiciones, principios, creencias, etc." de forma que "son racionales tales o cuales proposiciones, principios, creencias, etc." Pero, acto seguido, -y como si se entrase en propia contradicción- se reconoce que esto es "dogmático y, paradójicamente, irracional, porque no se 
ofrecen criterios mediante los cuales se adoptan tales o cuales proposiciones, principios, creencias, etc."1

Párrafos como el citado vienen así a confirmar ya de entrada lo resbaladizo o escurridizo, como decía, de toda temática que verse sobre lo irracional. Pese a ello aquí, al hablar de literatura religiosa, es posible suavizar la dificultad intrínseca de un concepto tan etéreo, como es lo irracional, porque lo vamos a entender naturalmente referido a la emotividad que, en mayor o menor medida, domina sobre el aspecto conceptual, es decir, racional, de la obra artística. O, dicho de otra manera, el predominio de lo sentimental -el amor, por ejemplo, que se mueve por caminos de lo irracional-, sobre lo intelectual, que transita por la senda de lo racional.

Y en la obra artística religiosa, que es una buena parte de la literatura producida en Alemania desde los orígenes del quehacer literario hasta el siglo XVII incluido, el peso que se reparten ambos formantes es muy distinto según los momentos de la historia literaria. Así, aspectos sobresalientes relativos a la literatura religiosa aproximan al tema de lo irracional entendido -según lo dicho- como sutilidad expresiva nacida de la sensibilidad emocional. ${ }^{2}$

Para su ejemplificación, el ámbito alemán proporciona sobradas fuentes y amplio caudal de información, lo cual no excluye la eventual referencia al entorno próximo de lo español, con el fin de resaltar paralelismos pero sin ningún afán de confrontar dos fenómenos literarios, y lejos por tanto de cualquier sujeción rígida a la comparatística.

Claro está, porque resulta evidente, que un título como el propuesto tan sólo permite, en el breve espacio de unas páginas, revisar algunas cuestiones de interés; por eso no es el pormenor de la concreta obra literaria o de un determinado autor lo que aquí interesa, sino el detenimiento en un concepto, lo irracional, aplicado a un campo más vasto -un tipo de literatura con características propias, como es la religiosa- porque es eso precisamente lo que puede dar pie para intentar abarcar el asunto desde perspectivas más generalizadoras. De ahí que sea obvio que ni el detalle preciso ni el dato concreto puedan tener cabida en este momento; ni tampoco interesan excesivamente, pues lo que importa aquí es el fenómeno literario religioso en sí y en un preciso mundo cultural, el alemán, pero que participa de similares fuentes de enriquecimiento de las que se nutren otros espacios culturales europeos, como lo es -y ciertamente de no nimia importancia- el Cristianismo.

Por supuesto, el tema que nos ocupa es amplio; sin duda excesivo, porque ubérrima es la literatura de la que hablamos y porque nada menos que en el lapso de tiempo de la historia cultural de la época denominada antigua lo religioso planea de manera omnipotente. No hay más que volver la mirada hacia la Edad Media -y no ya sólo en Alemania, sino en Europa- para confirmar que en gran medida la literatura no es sino expresión escrita del hecho religioso.

\footnotetext{
${ }^{1}$ José Ferrater Mora, Diccionario de Filosofía de Bolsillo I-Z. (Madrid: Alianza Editorial, 1989) P. 659.

${ }^{2}$ Por evidentes razones de espacio, y siguiendo un criterio basado en la dimensión poética de la diversidad textual que ofrece el panorama alemán escrito del medievo, no entran aquí en consideración textos menores; así, del amplio panorama de lo religioso en sus variadas manifestaciones textuales durante la etapa medieval alemana se exceptúa toda la llamada "Kirchliche Gebrauchsprosa", es decir, aquellos textos catequéticos de más interés lingüístico y cultual que estrictamente literario, como son "Taufgelöbnis", "Beichtformel", y las principales oraciones que comienzan a difundirse, en variantes dialectales del alemán antiguo, por mandato de Capitulares que imponen el conocimiento de la fe cristiana en los territorios alemanes.
} 
Pero es que además, por lo que atañe a Alemania, finalizado el medievo, ya en época de Reforma y Contrarreforma, la lucha religiosa invade buena parte de una literatura que, en los distintos géneros, muestra con frecuencia el desapego de lo estético en textos literarios convertidos en arma arrojadiza, a veces incluso en invectiva personal, contra todo un conjunto de ideas religiosas o posturas particulares. ${ }^{3}$

Pero es más, en Alemania la religiosidad de tipo místico, con origen medieval, pervivencia en el Humanismo e intensificación en el Barroco, abona el terreno para el estallido idealista y romántico inexplicable de no haberse producido -junto a otros factores- el pietismo ${ }^{4}$ protestante, verdadera actitud irracionalista y punto de apoyo de la sensibilidad literaria de fenómenos como la Empfindsamkeit o el irracionalismo del Sturm und Drang. ${ }^{5}$

Dicho esto, no está de más hacer una salvedad. A saber: lo irracional, que en principio puede ser propio de literatura de diverso tipo, no es ni tiene por qué ser patrimonio, ni siquiera distintivo o cualidad genuina de alguna literatura religiosa alemana, contrariamente a lo que a primera vista pudiera parecer por la evidente conexión del contenido textual religioso con lo escatológico. En consecuencia, cuando el texto poético religioso se aproxima o entra en lo que convencionalmente cabe ser calificado de irracional, en ocasiones la explicación tal vez haya de buscarse en el aspecto formal del texto, no en su temática, en su contenido conceptual siempre presente por mucha que sea la sutileza de la que el autor ha hecho gala a la hora de componer la obra.

\footnotetext{
${ }^{3}$ Paradigmático al respecto es el poema Von dem großen lutherischen Narren, de 1522, con el que Thomas Murner anatematiza a Lutero y su doctrina.

${ }^{4}$ El pietismo es una vía de comprensión e interiorización religiosa a partir del sentimiento individual, surgida a finales del siglo XVII en ambientes protestantes alemanes, y próximo por sus características a la mística. Figura señera es Philipp Jakob Spener (1635-1705), quien funda en Frankfurt los Collegia pietatis o asambleas de creyentes fuera de la Iglesia y contrarias a la ortodoxia eclesiástica, pues pensaban los pietistas que la Iglesia como institución se había anquilosado. El pietismo tendrá su reflejo en una literatura de base religiosa o irracionalista que da prioridad al sentimiento y se opone a la literatura ilustrada, como al Racionalismo en general. Junto a Spener, las personalidades destacadas del pietismo alemán fueron: Ludwig von Zinzendorf (1700-1760), fundador de asociaciones religiosas denominadas Wanderprediger y autor de cánticos religiosos místicos. Gottfried Arnold (1666-1714), quien sostenía que cualquier organización eclesiástica de la Religión era una degeneración de la fe, y por ello su fuente de inspiración fue el Cristianismo primitivo. En realidad estos pietistas lo que hicieron fue intensificar los ataques a la autoridad de la Iglesia iniciados ya por intelectuales de la "Übergangsphase" o "Vorrationalismus", es decir, de la etapa de transición del Barroco a la "Aufklärung".

${ }^{5}$ Antes de continuar, es preciso no obstante dejar claro que Religión se entiende aquí en su ya habitual sentido restringido, según el concepto que transmite la Sociología alemana del hecho religioso. Porque si a partir de las ciencias sociales, por religión se entendía con Durkheim el conjunto de respuestas a los dilemas existenciales humanos capaces de dar sentido al mundo, es claro que, de acuerdo con esa primera apreciación, todos somos religiosos, porque todos nos enfrentamos a la enfermedad, a la muerte y a la vejez. Pero, evidentemente, un concepto así de lo religioso nos llevaría a ampliar todavía mucho más la parcela literaria -de suyo ya extensa- a la que remitimos la cuestión de la irracionalidad. Por eso, tratando de acotar, es preciso partir de Max Weber, natural de Erfurt, la ciudad en la que se formó Lutero, y fundador de la Sociología moderna. Educado en un ambiente de tradición pietista, Max Weber restringe tan amplio concepto de religión, manifestado por su colega francés, al conjunto de creencias y rituales relativos a lo sagrado; y dado que es un hecho cierto que, en todo caso y con independencia de creencias personales, la distinción profano-sagrado reviste carácter universal, es permisible hablar de literatura religiosa cuando la manifestación literaria basa su razón de ser y tiene su punto de partida en convicciones acerca de lo sagrado.
} 
Y la explicación es bien simple, porque si al texto literario religioso subyace con frecuencia un saber teológico, ello es singularmente palpable en el ámbito literario alemán. ${ }^{6}$ Pero aún hay más, no sólo bajo el prisma de la ortodoxia institucional hablamos de racionalidad teológica; en una concepción de historia de la cultura, la Religión ha de entenderse como definitivo paso cualitativo hacia la comprensión de lo escatológico; porque supone la superación de lo mágico, y por lo mismo de cuanto ello comporta de actitud irracional e inexplicable, de mundos maravillosos, y su sustitución por planteamientos susceptibles de captación racional.

Pues bien, a partir de estos presupuestos y las anteriores acotaciones asentadas en Teología dogmática y fundamental, hagamos hincapié en una línea cultural -la religiosa- y su materialización literaria dentro del panorama alemán antiguo: De la misma manera que la filosofía, el sentimiento amoroso, la leyenda o el hecho histórico, la Religión es motor de creación literaria. En ocasiones, incluso con ella se inicia la literatura; así, en el mundo germánico el primer texto literario es una traducción bíblica a la lengua gótica, realizada por el sacerdote arriano Ulfilas. Y hasta tal punto ha sido la religión impulso creativo, que sin ella prácticamente ni siquiera habría habido producción literaria en algunas zonas, como en la correspondiente a la Alemania primitiva, mientras que en otras la ausencia de temática religiosa habría significado un considerable empobrecimiento de la literatura del momento.

Así, por ejemplo, sin rito religioso no habría surgido cuándo y de la forma en que lo hizo el drama: representaciones del nacimiento y pasión de Cristo, partes de la misa, etc., que si en España se inicia con el Auto de los Reyes Magos, del siglo XIII, correspondiente al ciclo navideño, en Alemania las piezas glosadoras de la natividad y pasión aparecen ya siglos antes cuando desde el IX y desde Suiza y Francia se extienden por Europa los Tropos, forma más perfeccionada de la Antífona existente ya desde el siglo III, y precursores de los Misterios de comienzos de la Edad Moderna.

Pero es que además, la aparente irracionalidad del sentimiento religioso y su plasmación en la obra literaria es nada menos que el primer paso hacia el nacimiento y consolidación de auténticos géneros de las literaturas modernas occidentales. Pensemos en la autobiografía, ¿existiría hoy de no ser por el aporte cultural cristiano? Porque lo cierto es que fuera del mundo cristiano occidental la posibilidad de encontrar textos literarios de tipo autobiográfico no es nada fácil. Veamos, pues, la cuestión ejemplificando en los dos ámbitos culturales ya aludidos: $\mathrm{Si}$, por ejemplo, los primeros brotes de autobiografía en España pudieran nacer con el Arcipreste de Hita -si bien se trata de una cuestión tradicionalmente controvertida-, las

\footnotetext{
${ }^{6}$ Naturalmente, podrá objetarse en seguida que la Teología no opera como las demás ciencias. En efecto, así es; hay puntos de partida incuestionables, inamovibles, bases indemostrables; pero es que precisamente en esto es en lo que reside su especificidad. De no ser así, hablaríamos de Filosofía o de Teoría de la Ciencia. Sin embargo -como sabemosello no significa imposibilidad de abordar racionalmente la materia religiosa; todo lo contrario, la misma Iglesia rechaza el fideísmo, y en consecuencia por Teología se entiende en la concepción cristiana: "la explicación y desarrollo científico -es decir, metodológico y sistemático- de la realidad de la revelación divina patente a la fe, con el fin de presentarla en lo posible como algo racional para el pensamiento humano." < Diccionario de Teología Dogmática. Director de la publicación Wolfgang Beinert. (Barcelona: Editorial Herder, 1990). Versión castellana de Claudio Gaucho, de la obra de Wolfgang Beinert (dir.), Lexikon der katholischen Dogmatik. (Friburgo de Brisgovia: Verlag Herder, 1987). P. 674.> Y en cuanto a su dimensión teleológica, "El fundamento y el centro de la teología es la revelación de Dios en Jesucristo. Su objetivo particular es la inteligencia crítica del contenido de la fe para que la vida creyente pueda ser plenamente significativa." <Diccionario de Teología Fundamental. Dirigido por René Latourelle y Rino Fisichella. Adaptó la edición española Salvador Pié-Ninot. (Madrid: Ediciones paulinas, 1992) P. 1411.>
} 
primeras muestras de al menos un subjetivismo estético en Alemania se encuentran ya en Parzifal, especie de novela biográfica de Wolfram von Eschenbach, del siglo XIII, e incluso tal vez en el Ruodlieb, primer intento de novela de caballerías a mitad del XI. De modo que la introspección sobre uno mismo o la descripción intelectual del sujeto, como formas de concebir el texto literario, de plantear la trama literaria, no tienen un origen casual. Es el sentimiento de culpa cristiano, de índole personalísima y estrictamente privada, lo que mueve todo un tipo de literatura que sin cesar discurre hasta la actualidad. No hay más que recordar el título de los primeros escritos autobiográficos: Confesiones, ya en San Agustín, ya en Rousseau, auténtico punto de arranque éste último de la corriente autobiográfica europea; y las confesiones no son sino una modalidad de exteriorización del examen de conciencia que postula la Religión.

En este sentido, cabe pues afirmar la presencia de un fondo religioso -si se quiere remoto, pero en todo caso cierto- en buena parte de las literaturas occidentales desde el s. XVIII, cuando la autobiografía y el prerromanticismo empiezan a despuntar. Si a esto unimos la religiosidad medieval como una constante literaria, que en países como Alemania pervive en cierto modo hasta finalizar el XVII, podemos decir que lo religioso se manifiesta de dos maneras a lo largo de toda la historia literaria: como literatura propiamente religiosa por su temática y finalidad, y como literatura laica pero en la que el sustrato religioso es más o menos determinante.

Se trata en ambos fenómenos antes citados -la autobiografía y el prerromanticismo- ${ }^{7}$ de profundos cambios en la cosmovisión europea decimonónica, de un irracionalismo, por oposición al racionalismo, que encuentra su más genuina expresión en el texto literario. Sin embargo, desde que surgen las sociedades modernas se produce un retroceso de lo sagrado, consecuencia de la racionalización de la cultura; de tal manera que el proceso de secularización conlleva una rebaja de la significación social de la institución y práctica religiosas. Bien es verdad que a su vez la proliferación de diversidad de cultos hace de la religión cuestión más personal que social.

Pero dejemos a un lado estos asuntos de aparición relativamente reciente en la civilización occidental y olvidémonos de la literatura a partir del XVIII; porque además, aunque en España ya se ha producido desde el Siglo de Oro, en Alemania es a partir de ese momento -el XVIIIcuando se hace verdaderamente palpable la diversificación del hecho literario; y ello sin mencionar otros factores, como son nuevas cosmovisiones, y planteamientos ideológicos y políticos, explicativos de que la literatura religiosa pierda cierto protagonismo, pasando a constituir hasta la actualidad una línea literaria, entre otras muchas.

Así -volviendo al punto de partida-, a la eclosión irracionalista laica de la Europa prerromántica precede toda una etapa de racionalidad teológica, sustentada paradójicamente en una vía de entendimiento del mundo próxima a lo intuitivo, a lo emocional, a lo irracional en suma, como es la religión, por lo demás auténtico basamento social, cultural y literario de

\footnotetext{
${ }^{7}$ Uno de tipo genérico o generológico, como se quiera - aunque en realidad ninguno de los dos términos es apropiado a la autobiografía, pues en ella de lo que hay que hablar es de estilo o forma textual más que de género-; el otro, -el prerromanticismo- protagonista, junto a la inmediata corriente romántica, de una radical transformación de la mentalidad europea.
} 
primera magnitud. Y la cuestión se hace más compleja si nos detenemos en grandes vertientes de la literatura religiosa, tales como la bíblica y litúrgica del medievo europeo, de índole más sociológica; y la introspectiva y espiritual de los místicos alemanes del medievo tardío, de claro sesgo psicológico.

Empezando por la primera, es un hecho sabido que toda la Edad Media no es sino un inmenso mundo religioso; la literatura medieval en Alemania, como en el resto de Europa, es literatura religiosa. Y ¿cómo se manifiesta esa religiosidad en la literatura medieval? Pues en forma de constante en la historia literaria, que si en nuestro país se hace patente desde casi el primer testimonio literario con un personaje como el Cid que ora y se santigua, o más aún después en el Mester de Clerecía, en Alemania sucede algo similar. En efecto, allí, y en el primer medievo, prácticamente todos los manuscritos susceptibles de ser considerados literarios -según concepciones estéticas actuales- transmiten contenidos religiosos, acusándose así por tanto la religiosidad en un fenómeno literario de tal manera que sin ella éste sería casi inexistente. Y no sólo en los siglos iniciales de literatura alemana, es decir, durante la época carolingia; también el resurgir de la literatura en alemán, tras el paréntesis latino del siglo X y primera mitad del XI, está determinado por la religiosidad: una literatura de fondo religioso que aborda problemas sobre la fe con intención de propagarla a través de una temática bíblica, o en torno a disquisiciones teológicas, y en la que el poeta hace uso de lenguaje solemne y pragmático.

Pero al mismo tiempo esa religiosidad se manifiesta con todo su dogmatismo desde el momento en que la omnipresencia de lo religioso impide que a nadie se le ocurra otros planteamientos diferentes o caminos de comprensión de la realidad ajenos a la vía de lo sagrado. Consecuentemente, el texto literario se propone codificar, con resultado práctico aplicable a la vida diaria, el amplio mundo simbólico de la creencia religiosa, surgiendo así la ejemplaridad como nota distintiva, de la que son buen testimonio los Bîspel, al igual que en España hacen los Exempla de Berceo o de Don Juan Manuel en su Conde Lucanor. Lo cual no es más que un detalle de la amplia función moral de una literatura que seculariza los procedimientos y recursos retóricos de la oratoria sagrada, dando lugar con ello a la aparición de importantes géneros literarios, como el sermón u otros textos asimilados, tales como el Muspilli del siglo IX en Alemania, que viene a ser un sermón de penitencia y llamada de atención acerca de las postrimerías o novísimos, es decir, muerte, juicio, infierno y gloria.

En definitiva, es la misión de instruir en la doctrina cristiana la que provoca todo un caudal de literatura religiosa, eficaz medio de resistencia contra el paganismo, de apartar a las gentes de la Alemania originaria de la poesía oral de procedencia germánica primitiva, como también era medio de contrarrestar los relatos juglarescos, en el caso español. A la literatura se le encomienda la tarea de hacer ver a las gentes el "sic transit gloria mundi", sobre todo a partir de Cluny con una literatura religiosa que observa la vida terrena desde la perspectiva teológica, y cuya finalidad última es la salvación; la brevedad de la vida, lo fútil de la existencia terrena, se convierte en máxima de casi toda la literatura religiosa: es el recuerda que has de morir, como reza el Memento mori alemán, la idea que machaconamente se repite en la literatura anónima y en la mayor parte de las obras de autoría conocida, como el Erinnerung an den Tod del fraile austríaco del siglo XII, Heinrich von Melk, ejemplo de auténtica actitud de oposición 
al mundo; mensajes y posturas algo comparables en cierto modo por su trasfondo a lo que siglos más tarde dirá en nuestro país Jorge Manrique en las Coplas por la muerte de su padre.

Pero también en el medievo, y junto a esa apreciación de la realidad a partir de la óptica religiosa, se produce literatura más sutil, más emotiva o impregnada del elemento maravilloso dentro del hecho literario religioso. Así lo corrobora la especial insistencia en la gineolatría; de manera que en Alemania, cuando lo profano empieza a sobresalir con un cierto protagonismo, y en la mayoritaria literatura religiosa predomina la línea pesimista de una visión negativa del mundo, surge con fuerza y apreciable nivel artístico una lírica mariana que canta a María en la liturgia y en la literatura. También en España contamos con sobrados ejemplos al respecto desde la Edad Media y más aún en lo sucesivo.

Caso similar es el de la hagiografía, de lo que si ya en Berceo tenemos un buen ejemplo, antes incluso en Alemania el poeta anónimo cantó a San Jorge, San Pedro ${ }^{8}$ y otros, no tanto al estilo biográfico cuanto al del canto de extraordinaria hermosura y emotividad, que hizo de algún texto ${ }^{9}$ rápido objeto de traducción latina a fin de dar ya entonces la mayor proyección posible a aquellas muestras de belleza literaria. Y es que la preferencia por el canto hagiográfico tiene su explicación en el carácter carismático del hagiografiado; en efecto, el carisma -término, por cierto, teológico-, es decir, las extraordinarias dotes personales del personaje bíblico, del santo, hacen de él figura digna de culto, modélica para los demás, y lo convierten en el medievo en uno de los grandes protagonistas del texto literario, junto al héroe o al cortesano.

En síntesis, toda la enseñanza y didactismo medieval se hallan bajo la atmósfera teológica; y la literatura, ya sea paráfrasis bíblica o exaltación lírica, está ligada a esa atmósfera de estricta racionalidad teológica. Y Alemania es especialmente paradigmática en el tema que nos ocupa, pues en general las primeras manifestaciones de literatura bíblica y litúrgica de cuño racionalista-teológico, que son el principio del fenómeno literario en aquel país, expresiones muy primitivas y previas todavía al nacimiento de las literaturas románicas, son claro exponente de que lo irracional ni es ni tiene por qué ser consustancial a la literatura religiosa. De tal manera que incluso no sería exagerado etiquetar esa inicial fase literaria alemana con notas distintivas que poco tienen que ver con lo que normalmente entendemos por irracionalidad cuando hablamos de un texto literario.

Así, esa literatura religiosa alemana, cuando no es sólo estricta traducción del texto bíblico, se aproxima a lo descriptivo y explicativo, de lo que es buena muestra el Liber Evangeliorum de Otfrid von Weißenburg; y tal rasgo de descripción es perfectamente explicable por cuanto es una literatura que se ocupa con notable interés en presentar la biblia y el ritual cristiano a los pueblos paganos centroeuropeos. Mas ello no excluye cierta sutilidad en la expresión cuando se abordan, por ejemplo, temas delicados por su difícil asimilación por parte de las gentes de pueblos de la Alemania originaria, cuya mentalidad estaba aún muy próxima a lo que había sido el mundo germánico primitivo, cuestión ésta que tuvo en especial consideración el

\footnotetext{
${ }^{8}$ Importantes poemas medievales en antiguo alto alemán, el Georgslied, muestra de leyenda hagiográfica del 900 aproximadamente; y el Petruslied, ejemplo de canto eclesiástico, el más antiguo en alemán y de una fecha en torno a la citada para el anterior.

${ }^{9}$ Es el caso de Galluslied, conservado exclusivamente en una traducción al latín realizada por Ekehard IV de St. Gallen.
} 
desconocido -y controvertido en la investigación filológica- adaptador del Nuevo Testamento a la lengua e idiosincrasia de los antiguos sajones, obra que conocemos con el nombre de Heliand.

Carece además, la literatura religiosa medieval alemana, de nota personal, de proyección del poeta en el texto; y ello por dos razones: en primer lugar, porque el poeta no se considera todavía digno de figurar ni de inmiscuirse en lo que escribe; lo que acarrea la anonimia generalizada. Y, en segundo lugar, porque aquella literatura religiosa cumplía una función extraliteraria al tener como meta evangelizar el territorio; en consecuencia, la subjetividad todavía no interesaba, era incluso inimaginable. Situación que persiste en siglos subsiguientes, diferenciándose el texto literario alemán de su coetáneo español en el que -cierto que de forma aislada- hay ya sin embargo atisbos de un incipiente tono personal desde Berceo y el Arcipreste que enlaza con Santillana y Juan de Mena ya en el XV. Aunque será ya a partir del Renacimiento cuando, con frecuencia sobre todo en literatura religiosa, el detalle personal, sigularísimo del poeta, su experiencia individual, dé colorido a una temática reiterativa; cosa que en Alemania se producirá con mayor retraso, si se exceptúan las composiciones de tipo místico.

Por último, en esta fase literaria a la que nos estamos refiriendo, primitiva dentro de la etapa denominada antigua, la literatura en Alemania es -según acabamos de apuntar- verdadera literatura de adaptación: adaptación del texto sagrado a una forma de sentir y a una cultura que procede del germanismo primitivo; y la adaptación tiene lugar respondiendo esa literatura religiosa medieval a actitudes calculadas que emanan del poder político carolingio que asume y hace suyos los objetivos de la Iglesia.

Ambas instituciones -la Corte Imperial y la red de monasterios y abadías entretejida en territorio alemán a modo de estratégica infraestructura que actualizaba entre los germanos las directrices de Roma-, para cristianizar la zona, propician un tipo de literatura en lengua vernácula que, aparentemente -como con frecuencia puede suceder en literatura religiosaofrece un contenido irracional. E incluso, otro tipo de manifestaciones poéticas más próximas al pueblo, a la creación de carácter colectivo, las llamadas "Bendiciones"10, rompen asimismo la antinomia irracional-racional; se trata de textos breves similares a fórmulas de conjuro paganas pero a partir de planteamientos cristianos que, plasmados por escrito en el siglo X, pervivieron muchos siglos en la cultura popular destacándose así la trascendencia que para las gentes de aquella recién cristianizada región centroeuropea tenía la invocación como remedio frente a los reveses de la naturaleza.

En definitiva, es tal la fuerza y presencia del hecho religioso conformador de la literatura vernácula alemana que, junto a la omnipresencia del latín, la lengua popular -el alemán- se

\footnotetext{
${ }^{10}$ Las "Segensformeln" proliferaron extraordinariamente porque eran recursos muy similares en su estructura a los sortilegios mágicos empleados en el ritual pagano de los germanos, todavía arraigados en la mentalidad de los pueblos de la Alemania primitiva. Aquellas fórmulas, herederas -por su parentesco estructural- de ritos mágico-míticomisteriosos basaban su fuerza en la palabra, sustituta ahora del signo rúnico. Entre otras, algunas de las más significativas son: Wurmsegen, con paralelismos en antiguo indio y en el ámbito bajo alemán, contra determinadas enfermedades; Wiener Hundesegen para proteger a los perros de caza de lobos y ladrones; Lorscher Biennensegen para que las abejas produzcan miel; Zürcher Hausbesegung para protegerse contra el diablo; Straßburger Blutsegen cuya finalidad es contener hemorragias; Ad equum errehet para la curación de caballos; Gegen Fallsucht contra la epilepsia.
} 
convierte en auténtico vehículo de la institución eclesiástica y en avanzadilla de la actividad misionera. ${ }^{11}$

Pasemos ahora a la segunda vertiente: la introspectiva y espiritual de los místicos. El misticismo tiene su gran momento en nuestro país en una etapa de extraordinaria creatividad que recorre todos los ambientes, y naturalmente el eclesiástico con la relevancia de órdenes religiosas de dominicos, jesuitas, etc. Por lo demás, grandes escritores renacentistas y del Siglo de Oro cuentan con indudable bagaje teológico, e incluso alguno de nuestros más insignes escritores se ocupa de toda clase de temas religiosos. A su vez, la poesía religiosa abunda tanto en esa época como cualquier otro género.

En Alemania, aunque la situación política, social y cultural en esa etapa difiere bastante de la española, en el plano de la literatura religiosa es de destacar un antidogmatismo renacentista empeñado en indagar por otras vías distintas de la escolástica tradicional, y en rebatir posiciones de la Iglesia, si bien en principio -y hasta la llegada de Lutero- sólo en lo que a aspectos formales se refiere, nunca cuestionando el dogma, es decir, fundamentos esenciales de la Religión.

Sin embargo, en seguida y ya durante todo el periodo barroco la literatura religiosa se diversifica como consecuencia de la lucha reformista y contrarreformista, aspecto este último en el que España también hará su contribución. El teatro de jesuitas y benedictinos en Alemania, y con él buena parte de la producción literaria del momento, se convierte en arma al servicio de la idea religiosa, motivo de lucha y enfrentamiento entre la postura tradicional y la innovación de la Reforma.

Pues bien, éstos años en los que simultáneamente la mística llega a su apogeo en España, y aunque no tan destacada se da también en Alemania, abonan el terreno para que en este último país se inicie hacia finales ya del XVII el pietismo: aquella similar vía de interiorización religiosa que ejercerá apreciable influencia en cultura y literatura posterior. Pero el origen de lo místico se inicia en Alemania muy tempranamente y con consecuencias literarias de primer orden; porque la religiosidad mística del medievo alemán va a introducir pluralidad de factores de especial relieve que suponen extraordinario enriquecimiento de la literatura en lengua alemana: de un lado, y junto a todo un mundo de éxtasis visionario ${ }^{12}$ de personajes de procedencia dispar, la gran figura del misticismo -Eckhart- significa ya la combinación de filosofía y literatura, algo relativamente frecuente -desde entonces y hasta hoy- a lo largo de la historia literaria alemana. En efecto, es una explicación o exposición del dogma a la manera filosófica de un neoplatonismo lo que verdaderamente hace el padre del misticismo medieval alemán con más que notable influjo en su época. Pero, de otro lado, las experiencias místicas de moradores de conventos y, sobre todo, la obra del citado Eckhart, y de sus continuadores, Seuse o Tauler, conforma nuevos estilos, nuevas formas de escribir propias de un incipiente género epistolar, por ejemplo, $\mathrm{y}$, en definitiva, da consistencia por primera vez a la prosa alemana. Es así una forma de religiosidad, la de tipo místico, la que contribuye definitivamente

\footnotetext{
${ }^{11}$ Cfr.: "Deutsch als Missions- und Kirchensprache", en: Dieter Kartschoke, Geschichte der deutschen Literatur im frühen Mittelalter. (München: dtv, 1990)

12 Véase sobre la cuestión el epígrafe "Visionen", en: Achim Masser, Bibel- und Legendenepik des deutschen Mittelalters. (Berlin: Erich Schmidt Verlag, 1976)
} 
nada menos que al establecimiento y consolidación de una prosa en lengua alemana, que de alguna forma tendrá su continuación en otras manifestaciones literarias religiosas más combativas ya en tiempos de la Reforma.

Los inicios del misticismo en Alemania corresponden, por tanto, a la fase tardía del periodo medieval; fase cuya literatura en lengua alemana no ha merecido igual intensidad en su estudio como el resto de la producción literaria alemana en ese milenio ${ }^{13}$, y en la que se habla de decadencia estética, a mi juicio de manera errónea, pues si bien ha quedado atrás la época cortesano-caballeresca, es decir, el gran momento de la literatura medieval alemana, es ahora cuando se produce auténtica dispersión de géneros literarios nuevos, temas y estilos que serán la base del lenguaje poético y literario alemán. Y, dentro del fenómeno literario religioso, es ahora el drama con escenas litúrgicas ya mucho más desarrolladas una de las grandes aportaciones del momento, además precisamente de la mística, esa corriente de interiorización religiosa pionera en Europa por su originalidad. A la literatura mística del medievo tardío se debe además el enriquecimiento de la lengua literaria alemana por el cúmulo de imágenes, metáforas y simbología que aporta, junto a todo un caudal de términos abstractos denotativos de los procesos internos experimentados en la vivencia mística.

Evidentemente, no es cuestión aquí de matizar respecto del fenómeno místico, pero sí de mencionar -para el tema que nos ocupa- esa especial forma literaria de religiosidad, que coexiste paralelamente junto a otra literatura religiosa durante buena parte de la fase que denominamos antigua. Naturalmente, sabemos que misticismo no equivale a cristianismo; de hecho es una singular forma de devoción interconfesional, que en el ámbito cristiano adopta formas peculiares. Por misticismo, pues, se entiende un singular estado psicológico, en ocasiones irracional a los ojos del lector del texto literario, racional según el punto de partida de una fe arraigada, que opta por la contemplación profunda de lo divino como forma existencial; en sí lo místico es por lo tanto una metafísica que, aunque no se le oponga, difiere de la teología dogmática.

Por eso la actitud mística, cuando se intenta transmitir por escrito, puede conducir a una forma irracional de expresar en el texto literario un convencimiento teológico racional. Porque el místico es aquél que, realizando un extraordinario ejercicio de voluntad, obtiene un don divino consistente en la unión metafísica con Dios; es decir adquiere el conocimiento directo de Dios por vía sobrenatural, no racional. De tal forma que, desde el convencimiento o racionalidad teológica, y tras un proceso psíquico, se llega a la irracionalidad del éxtasis, estadio último que el poeta pretende transmitir en su texto literario. Y es irracional porque nace de la fuerte voluntad de unión con la divinidad por vía del amor, de manera que el fin perseguido por el místico es la fusión de alma y Dios. Para ello, el poeta místico vislumbra estados de perfección y atributos del ser inaprehensibles por vía racional. Pero esto, ¿cómo lo percibimos nosotros?, ¿cómo captamos el significado irracional o simbolizado del texto místico? Pues -de igual modo que se ha dicho para otros tipos de poesía de apariencia

\footnotetext{
${ }^{13}$ Véase al respecto una de las mejores obras publicadas sobre la literatura del final de la Edad Media alemana: Wentzleff-Eggebert, F.-W., Deutsche Literatur im späten Mittelalter, 3 vols., Reinbeck 1971; y, sobre el fenómeno místico en concreto y en la misma época, del mismo autor: Deutsche Mystik zwischen Mittelalter und Neuzeit, Berlin 1969.
} 
fuertemente irracional- por medio de asociaciones que captamos emotivamente, no lógicamente. ${ }^{14} \mathrm{Y}$ si eso es así es porque el impulso místico es siempre irracional. Y de ahí que al autor de un poema de fuerte carga simbólica -como bien puede ser el de un texto místico, en el que se utiliza el símbolo como herramienta fundamental- pueda sucederle lo que se ha dicho para similares casos de poesía profana: que incluso ignore el significado conceptual de su escrito, sin que ello presuponga necesario desconocimiento de lo que expresa de manera intuitiva. $^{15}$

Claro está que esto ha sido motivo de discusión en la crítica literaria, polémica en la que no se va a entrar aquí porque, aparte de conducirnos por caminos especulativos interminables, las diversas posturas que se pueden tomar al respecto no hay manera de reducirlas a la unanimidad, cosa por lo demás natural en el plano puramente teórico.

Por su evidente interés, una breve incursión en el asunto no está sin embargo de más. Carlos Bousoño ha dicho que "La poesía más aparentemente irracional (...) lleva (...) en su seno, como sustentáculo, un conglomerado de significación perfectamente pensable desde el plano lógico". A tal aserto se ha respondido igualmente manifestando radical oposición: no; hay poemas carentes "en absoluto de sentido asequible a la razón", sólo tienen "sentido poético"; "el significado de esos poemas no tiene posible reducción conceptual" porque en ellos no es posible "abreviar" en un concepto la emotividad poemática. ${ }^{16}$ Quienes inician el debate, contraatacan: sí es posible; todo se puede enunciar de manera inteligible -racional, diríamos- tras el análisis, o sea, tras el estudio y disección del texto.

Pues bien, esto mismo lo podemos aplicar también a la originaria concepción del símbolo, tan utilizado en la literatura religiosa, y sólo en parte concomitante con lo que muchos siglos después se entendería por poesía simbolista en la acotación del sentido que Papadiamantopoulos, es decir, Jean Moréas, da al término símbolo, de nueva acuñación en el declinar decimonónico: "La poesía simbolista es enemiga de lo didáctico, de lo declamatorio, de la falsa sensibilidad, de la descripción objetiva"; ${ }^{17}$ claro está que lo que aquí se pretendía era el distanciamiento y oposición al realismo, positivismo y cientifismo de la época, pero perviviendo -eso sí- el rasgo originario de lo simbólico: el misterio, o sea, lo irracional como forma de enfrentarse al mundo. Y la forma de aproximarse al misterio es la ininteligibilidad de un texto débil en relaciones lógicas que sólo quiere ser sugestivo y arrastrar hacia los dominos del ensueño.

Pero, hay que insistir: quede en el aire esta cuestión, porque además el término "símbolo" ha adquirido hoy diversidad de connotaciones al hacerse polisémico, con infinidad de aplicaciones en más de una rama del conocimiento: lingüística, semiótica, etc., y que no vienen al caso. De lo que aquí se trata es de recordar el símbolo como recurso literario próximo a la metáfora o, mejor, a la alegoría, es decir, con su originaria y tradicional función especialmente desarrollada en la literatura religiosa desde muy antiguo.

\footnotetext{
${ }^{14}$ Cfr.: Carlos Bousoño, Teoría de la expresión poética, v. I. (Madrid: Gredos, 1976) P. 196.

${ }^{15}$ Idem, p. 39.

${ }^{16}$ Idem, v. II, pp. 142-143.

${ }^{17}$ Carlos Pujol, "Baudelaire y los simbolistas", en: Historia universal de la literatura, v. IV, La literatura del siglo XIX. (Barcelona: Orbis-Origen, 1982) P. 247.
} 
Dejando fuera, por tanto, el plano teórico que nos desvía por otros derroteros, hay que concluir que la literatura mística -y por tanto toda esa forma también de religiosidad reflejada en textos de "literatura visionaria" del medievo alemán- no es sino una plasmación en forma artística de la racionalidad teológica, porque precisamente con el juego del lenguaje el poeta religioso utiliza el símbolo como eficaz instrumento de transmisión de conceptos. Y es natural; no en vano el símbolo como recurso literario, incluso el término que lo designa, nace con la literatura religiosa allá por el siglo IV y se convierte en habitual modo de expresión de los ambientes cultos durante todo el medievo, haciendo de nexo de unión entre irracionalidad literaria y racionalidad teológica. Recuérdese -por establecer algún paralelismo clarificador- el caso de algún poeta de nuestro entorno cultural -como San Juan- que refleja por escrito su éxtasis místico sin intención de publicar o -a lo sumo- pretendiendo dar a conocer su obra a los más allegados, miembros de la orden religiosa capaces de captar el contenido teológico de un texto literario irracional a los ojos del profano; textos, por ejemplo, plagados de sustantivos en mera sucesión rítmica, en los que falta toda estructura sintáctica, verbos u otros elementos oracionales que den armazón lógica al discurso. Son éstos auténticos casos de obra literaria abierta a toda clase de interpretación, pues el poeta lo único que ha hecho es evocar imágenes.

Pero la riqueza y variedad de formas que ofrece la literatura religiosa alemana antigua permite, a su vez, distinguir incluso dentro de la gran corriente mística; de tal modo que simultáneamente a la neta experiencia fuertemente subjetiva, intuitiva e irracional, exteriorizada en un embrionario género epistolar surgido especialmente en los conventos femeninos y conformador de toda una "Frauenmystik", de una literatura femenina que no es sino expresión de vivencias religiosas, se unen otras aportaciones de una mística más esencialmente filosófica que es la que precisamente incidirá de manera más evidente en el desarrollo del lenguaje literario alemán. Es así éste el caso del místico alemán Eckhart -aún hoy no sabemos si precursor o no, junto con otros compatriotas del medievo tardío, de los carmelitas españoles- en cuya obra la constante mezcla de saber escolástico y experiencia contemplativa minimiza la irracionalidad literaria, aparente irracionalidad como he dicho. Sin embargo y pese a ello, él mismo da por sentado que quien le lea no es capaz de entender lo que dice ya que la lectura no la realiza el lector a través de su corazón, del corazón de Eckhart. Y no le faltaba razón: andando el tiempo aquella dificultad de comprensión fue aprovechada por la ilusoria megalomanía del nazismo que interpretó frases como: "soy tan eterno como Dios" en clara referencia a la inmortalidad del alma- en el sentido bien tergiversado del superhombre y el "Reich" milenario.

En fin, el trastrueque de esquemas racionales en la poesía mística, cuya finalidad es la connotación sugestiva, se fundamenta en la seguridad de la vivencia experimentada por el poeta; es decir, en una actitud real e íntima, personal, vivida sólo por quien escribe y si acaso, algo similar, nunca igual, por un reducidísimo número de personas. $\mathrm{Y}$ vivencias de esa naturaleza no es posible revivirlas, reproducirlas, por escrito. Por eso el problema estriba en que el texto poético nunca es capaz de transmitir la experiencia mística, sólo tal vez evocarla; y por eso la racionalidad teológica se vuelve en el texto poético irracionalidad literaria.

Como inciso antes de concluir, y ya que se ha hecho alusión a dos culturas, no está de más esbozar, a modo de apunte final y con la expresada intención de trazar algún paralelismo, un 
par de rasgos sobresalientes de la racionalidad teológica explicitada en el texto literario religioso.

Además del permanente afán exegético, común a ambos países mencionados, durante la fase aquí glosada, la literatura religiosa alemana muestra en ocasiones proximidad a la especulación filosófica, apego por lo ontológico, mientras que en nuestro país se ha subrayado la familiaridad con que el escritor trata el tema religioso, adoptando en su intención moralizante posturas más netamente psicológicas y éticas.

De otro lado, a la diversidad de perspectivas en el panorama alemán, anticonformismo incluso que será en su momento nada menos que punto de partida del cisma, se resiste en España la unidad y conformismo de un tradicionalismo con muy escasas vacilaciones heterodoxas.

Por último, la ascética -definida por algún erudito como propedéutica que lleva al misticismo ${ }^{18}$ - no tiene en la literatura alemana la repercusión alcanzada en nuestro país.

Hecho el inciso, en síntesis ya, lo importante es que, lejos de absolutizar el elemento emocional, y consecuentemente hablar de irracionalidad -con independencia de que se esté o no de acuerdo en ver en el análisis la vía de reducción significativa del texto-, cuando nos referimos a literatura religiosa, sin distinción de nacionalidad -incluso aquella planemante simbolizada-, lo irracional es la apariencia y formalidad de algo que se presenta en forma literaria pero que indiscutiblemente responde a convicciones sin duda aprehensibles, es decir, racionales.

Aunque no se trate aquí de equiparar con otros tipos de literatura, tampoco hay por qué excluir casos análogos, incluso más exagerados que los de la mística, en diferentes esferas de la creación artística; y en ese sentido, diríase que la espontaneidad que pudiera intuirse en un poema absolutamente irracional, proyección escrita de un concreto estado psicológico, de una vivencia personal, o simplemente peculiar manera de reproducir la realidad, tal vez no tenga exacta correspondencia con otro formalmente similar de carácter religioso, por ser en este caso el resultado final un producto sin posibilidad de materialización escrita, de no ser por la ardua gestación que supone toda actitud mística, o por el motivo teológico que dio pie para el canto o el poema en concreto.

En resumen, las formas de religiosidad que ofrece la literatura alemana antigua entran prácticamente todas ellas en las grandes vertientes aquí apuntadas, naturalmente con subvertientes y ramificaciones dentro de un amplio abanico de posibilidades; no obstante, lo dicho acerca de la división aquí propuesta, en dos grandes líneas de literatura religiosa alemana antigua, no quiere ser sino una primera aproximación a un tipo de manifestación del fenómeno literario alemán en aquella época, que bien merece futuras reflexiones y planteamientos que hagan posible seguir revisando y profundizando acerca de no pocas cuestiones relativas a esa etapa de la literatura alemana denominada antigua.

${ }^{18}$ J. L. Alborg, Historia de la literatura española, v.I, Edad Media y Renacimiento. (Madrid: Gredos, 1979) P. 877. 
